\title{
A Novel Single Switch Non Inverting Buck Boost Converter based Maximum Power Point Tracking System
}

\author{
Aamir Khan ${ }^{1}$, Hari Kumar Singh ${ }^{2}$ \\ ${ }^{1}$ Department of M. Tech (Dual Degree) Electrical + Energy Engineering, Suresh Gyan Vihar University, Jaipur, Rajasthan, India \\ ${ }^{2}$ Associate Professor, Department of Mechanical Engineering, Suresh Gyan Vihar University, Jaipur, Rajasthan, India
}

\begin{abstract}
Maximum Power Point Tracking, frequently referred to as MPPT, is an electronic system that operates the Photovoltaic (PV) modules in a manner that allows the modules to produce all the power they are capable of. MPPT is not a mechanical tracking system that "physically moves" the modules to make them point more directly at the sun. MPPT is a fully electronic system that varies the electrical operating point of the modules so that the modules are able to deliver maximum available power. Additional power harvested from the modules is then made available as increased battery charge current. MPPT can be used in conjunction with a mechanical tracking system, but the two systems are completely different. A solar module can't transfer maximum power to the load itself due to impedance mismatch. A maximum power point tracking (MPPT) system could be employed to have the maximum power. A new MPPT system has been developed using Buck-Boost type DC-DC converter. The system is highly efficient and robust. PIC16F73 microcontroller has been used to control the DC-DC converter output. PV module output power is measured using microcontroller. The output power is compared with the previous module output power and the duty cycle of the converter is adjusted continuously to track MPP. This process repeats until the output power reaches near to the maximum power point. In this paper, a maximum power point tracking (MPPT) system is developed using two-switch non-inverting buck-boost converter. Perturb and observe (P \& O) MPPT algorithm is used to transfer maximum power from the PV panel which is executed using a microcontroller.
\end{abstract}

Keywords: PWM, buck boost converter, MPPT, microcontroller, preturb and observe

\section{Introduction}

This paper presents the current development the solar system is gaining important importance in conference the tasks of the ultimatum in the power sector due to its domestic and easy arrangement. To achieve a unchanging voltage from an input supply solar PV module that is greater and lesser than the power output and a great efficiency and smallest undulation buck boost converter is mandatory in the system for housing power manufacture. DC to DC converters marks it imaginable to professionally transform a $\mathrm{DC}$ voltage to moreover a lesser and greater required voltage. DC to DC converters are particularly valuable for solar PV module maximum output power tracking system where the unbiased is to attraction maximum conceivable power from solar PV module at all times and charge the battery nonstop using PWM technology to reach the improved efficiency and irrespective of the load. These papers also present the design and applications of projected buck-boost converter based PWM technology with MPPTs charge controller are used for enhancing the employed condition.

\section{Literature Survey}

This paper presents, the Energy particularly alternative source of energy is vital for the growth of a country. In future the world forestalls mounting more of its solar energy resources possible as a substitute solar energy source to overwhelm the determined deficiencies and irregularity of power supply. In command to make the most of the power output the scheme mechanisms of the solar photovoltaic system should be enhanced. For the optimization concentrated power point tracking is a talented technique that grid bond inverters and solar battery steeds and comparable devices use to grow the extreme imaginable power from one and more solar PV modules. Amongst the different approaches used to trail the maximum power point system. preturb and Observe technique is a type of approach to enhance the power output of solar PV module. In this technique the controller regulates the voltage by a slight amount from the solar PV module and procedures power if the power rises and additional modifications in that way are strained until power no lengthier growths. In this investigation paper the scheme presentation is perturb and observe method using DC to DC converter. By fluctuating the duty cycle of the DC to DC converter and the source impedance can be coordinated to fine-tune the burden impedance to increase the efficiency of this structure.

\section{Experimental Setup}

We have design and construct the circuit diagram and hardware prototype model of Design and construction of A Novel single Switch Non inverting Buck Boost Converter based Maximum Power Point Tracking System. The circuit diagram and prototype hardware of A Novel Two Switch Non inverting Buck Boost Converter based Maximum Power Point Tracking System shown in below. 


\section{International Journal of Science and Research (IJSR) \\ ISSN (Online): 2319-7064}

Index Copernicus Value (2013): 6.14 | Impact Factor (2014): 5.611

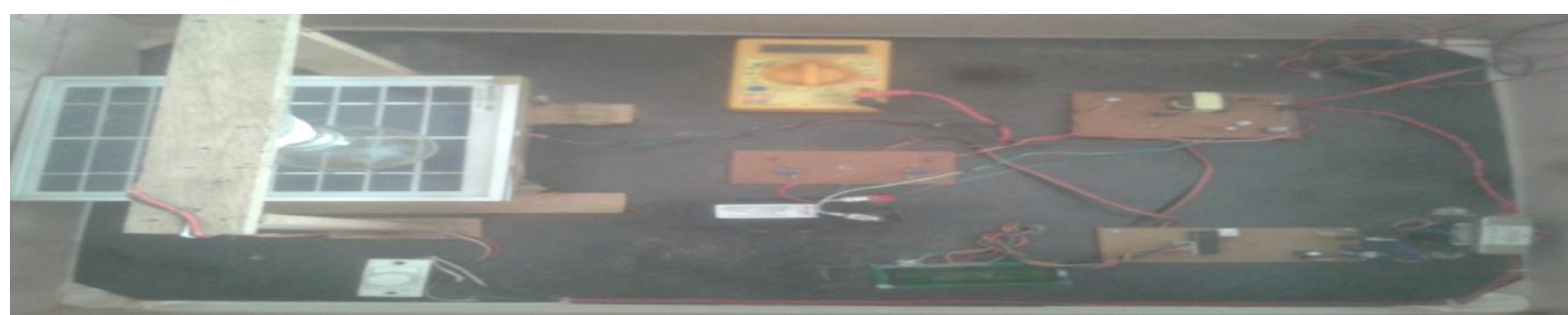

Figure 1: System runs on battery with AC power supply

\section{Working and Methodology}

In this system we have used dc to dc converter or buck-boost converter which is working for step up voltage and maintain the output voltage with constant voltages. Some fluctuations of radiation and voltage buck-boost converter maintain the voltage and it supply power to lead acid battery and load for battery charging and running with the help of blocking diodes; the working of blocking, it block the reverse current flow from battery to solar PV panel. The buck-boost converter is also connected to microcontroller for the controlling of output and compared with or without output voltage of this system and turns control the MOSFETs according to algorithms with connected to resistors for the showing the charging of battery, how many power provides solar PV module and how many power converts through buck-boost converters. Output of this system depends upon the solar radiation if larger amount of radiation falls on solar PV module then it converts maximum power but if larger amount of radiation does not fall on solar PV module then it does not converts more power due to lack of radiations.

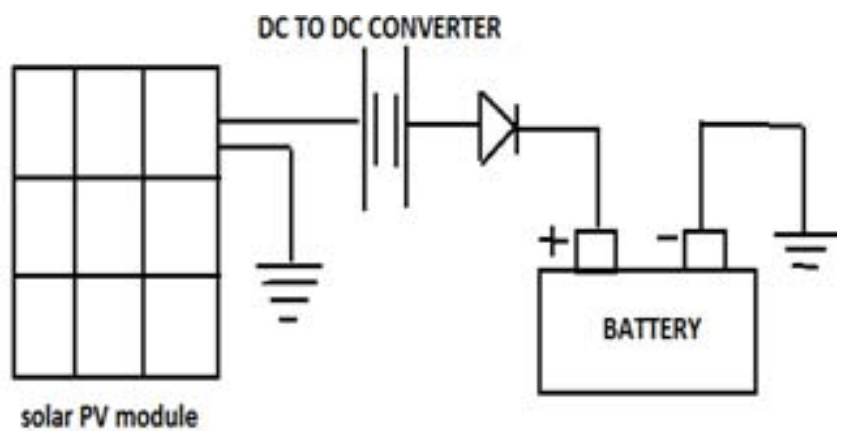

Figure 2: Block diagram of this system

\section{Waveform and Discussion}

This chapter provides the waveform and discussion of controlling of a novel single switch non inverting buck boost converter based maximum power point tracking system and also provides the duty cycle waveform which was taken from the CRO with pulse- with- modulation PWM technique.

\section{Observation 1:}

This waveform is generated by microcontroller using Pulse Width Modulation technology with a base frequency of 1 Khz. The positive duty cycle observed here is $70 \%$ while negative duty cycle is $30 \%$. The wave form is a variable duty cycle square waveform as seen in the picture below, taken from the $\mathrm{CRO}$ at the time of operation.

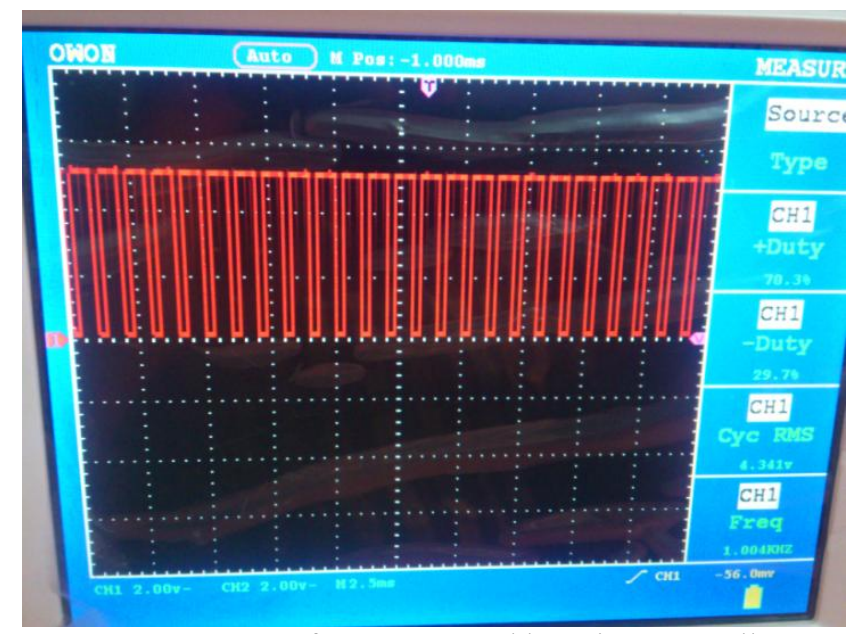

Figure 3: waveform generated by microcontroller

\section{Observation 2}

This waveform is generated or observed at the drain point of the MOSFET, the solar voltage will be chopped in inverse of the PWM generated by the microcontroller, this chopping will result in the conversion of this observed voltage in ac form across the ferrite transformer.

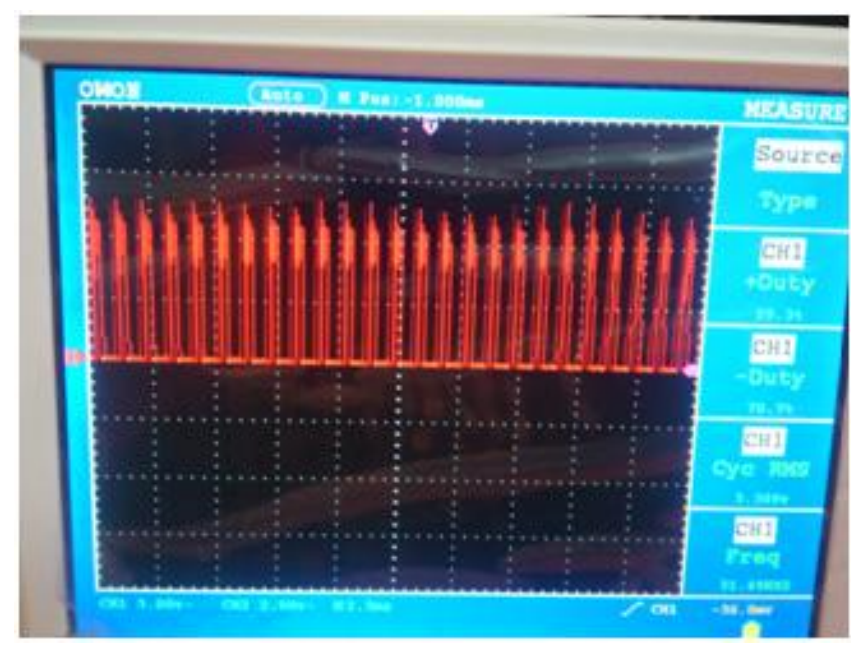

Figure 4: Waveform at Drain Point of MOSFET

\section{Observation 3}

This waveform is observed at the primary side of the ferrite transformer, this is the chopped form of Vsolar which is observed as AC signal across the primary side of ferrite transformer. 


\section{International Journal of Science and Research (IJSR) \\ ISSN (Online): 2319-7064}

Index Copernicus Value (2013): 6.14 | Impact Factor (2014): 5.611

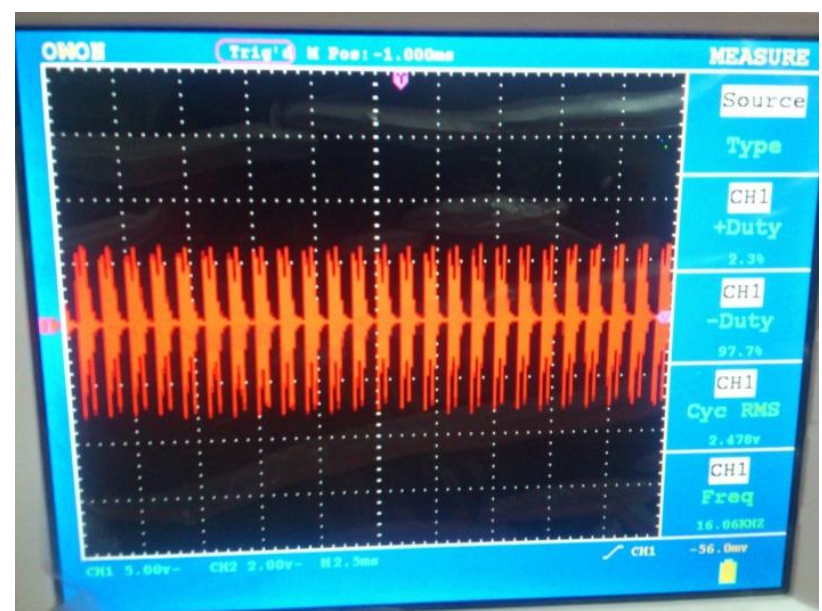

Figure 5: Waveform at primary side of ferrite transformer

\section{Observation 4}

This wave form is observed at the secondary side of the ferrite transformer, as we can observe in the waveform, the voltage is increased at the secondary side of the transformer. This simply means the chopped solar voltage has been increased by the ferrite transformer.

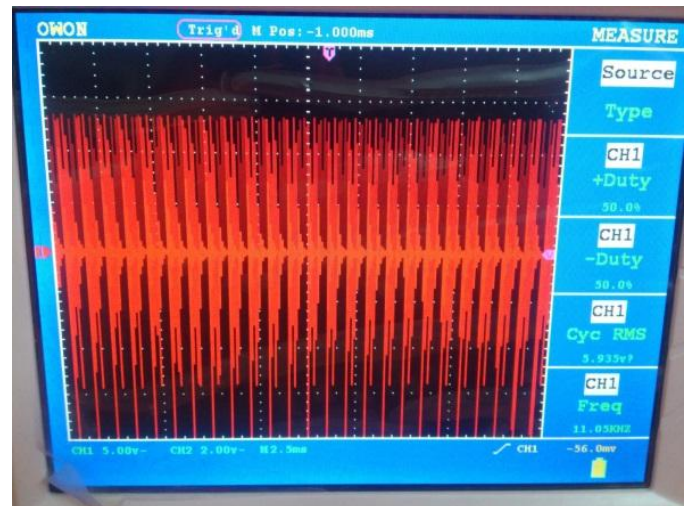

Figure 6: Waveform at secondary side of ferrite transformer

\section{Result \& Discussion}

This chapter provides the results from all above waveform and discussions; we have found the results of a single switch non -inverting buck boost converter with using MPPTs is good technology to improve the power performance of solar PV module. In this system we have used buck-boost converter to improve the power performance of solar PV module and we have seen from all waveform discussion the PIC16F73 microcontroller control the output power of this system and also compared the output power with MPPTs to without MPPTs. The comparison of this power of solar PV system with or without MPPTs displayed on the LCD and MOSFETs is used for controlling the turns of DC to DC converter according to algorithms. This technology's the output power reaches near to maximum power point tracking system because the output power of solar PV module depends upon the solar intensity. If solar intensity is higher than it will produce more power and if solar intensity is not higher than it will not produce higher power but buck- boost technology or DC to DC converter and MPPTs improves the power of solar PV module under the variation of intensity like low or high and it will be maintained the output voltage of solar PV module. From all above discussion we have found the result of a single switch non-inverting buck-boost converter has higher voltage with compared the simple solar PV module. So, this is the best technology to improve the power performance of solar PV module

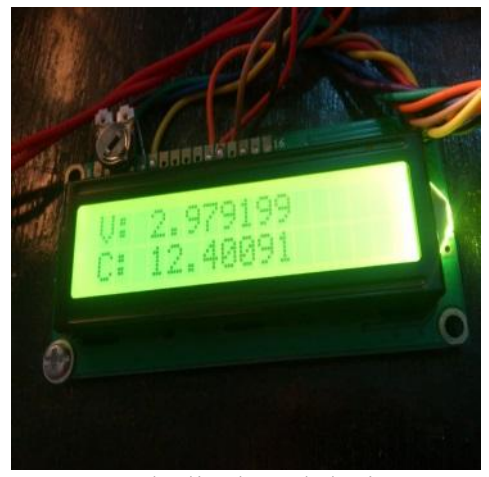

Figure 7: Result displayed during operation

\section{Conclusion}

The MPPT charge controllers can be used to utilize maximum power out of solar panels instead of investing in more number of solar panels. This chapter provides the conclusion from all above waveform, discussions and results; we have found the conclusions of a single switch non-inverting buck boost converter with MPPTs is the best technology to improve the power performance of solar PV module. This technology is approximately about $90 \%$ efficient. A maximum power is output power is generated with MPPTs connected to load as compared without MPPTs system. So, for higher load and low cost MPPTs system is better choice to provide maximum power as compared from solar PV module.

PV system with efficient battery charging controller by proper design equations has been presented in this work. The system effectiveness of the proposed controller has been highlighted by checking the charging and discharging currents of the battery.

\section{Future Scope}

This chapter provides the future scope of a single switch non-inverting buck boost converter with MPPTs is the best technology to use in the future because it can be improved the power performance of solar PV module. We know that the power consumption is going to increase day by day and solar PV module are not more efficient than a buck boost converter or DC to DC converter and MPPTs system is better choice to reduce these problem because it is more efficient and it can be reduce the power consumption problem and it can be improve the power performance of solar PV module. So, it is the best technology to use in future.

\section{References}

[1] Tushar Srivastava, Dr. P.B.L Chaurasia, Hari Kumar Singh, Experimental Study To Calculate Fuel Cost Effectiveness For 


\section{International Journal of Science and Research (IJSR) \\ ISSN (Online): 2319-7064}

Index Copernicus Value (2013): 6.14 | Impact Factor (2014): 5.611

[2] FABRICATED SOLAR POWERED CAR OVER THE GASOLINE FUELLED VEHICLE AND AIR POLLUTION FROM ROAD VEHICLES IN URBAN INDIA- VOL 2 ISSUE 8. 2014, PG-(32-38)

[3] Arvind Kumar, Gaurav Acharya, Hari Kumar Singh, Effective use of Roof Surface Area for Electricity Generation using Solar Energy: A Case Study of Jodhpur, PISER, Vol.02, Issue: 04, june, 2014, PG(137-141),

[4] Neeraj Kumar, Dr. P.B.L. Chaurasia, Hari Singh, Analysis of Multi Slope Pyramid Shaped Solar Stills Facing Sun with an Angle of $45^{\circ}$ IJMEIT, Vol. 2 Issue 12, December 2014, PG- (913-916)

[5] Pawan Kumar Tiwari, P.B.L Chaurasia, Experimental Investigation of the Effect of

[6] Temperature Variation on Photovoltaic Cell and Efficiency Improvement by WaterCooling, IJSR Volume 3, Issue 6, June 2014.PG-(1661-1664)

[7] IRFAN AYAZ, HARI KUMAR SINGH, AFJAUL ANSARI, AMIR AZMY, MD. ZEYAUL MUSTAFA KHAN, DESIGN \& DEVELOPMENT OF SUITABLE ESTABLISHMENT TO STABILIZE, RECTIFY AND ENHANCE ELECTRIC CURRENT FLOW, GENERATED BY SOLAR PARABOLIC DISK COLLECTOR, IJSET- VOL 3, ISSUE 1, JAN-FEB 2015, PG-(302-307)

[8] Sree Manju, B Ramaprabha, R Mathur B.L, Design and Modeling of Standalone Solar Photovoltaic Charging System proceeding by International Journal of Computer Applications (0975 - 8887) Volume 18No.2, March 2011

[9] A .Harish, M. V. D. Prasad, Microcontroller Based Photovoltaic MPPT Charge

[10] Controller proceeding by IJETT, Volume4, Issue4April 2013PG-(1018-1021)

[11]Dr. B.J. Ranganath, Mr. Amurth R.T, Design of DC/DC Buck-Boost Converter Charge Controller for Solar Power Applications proceeding by GRA - GLOBAL RESEARCH ANALYSIS, Volume 2, Issue 7, | July 2013

[12] Shiba Arora, Pankaj sharma, Modelling \& Simulation of Photovoltaic System to Optimize the Power Output Using DC-DC Converter, IJAREEIE, Vol. 3, Issue 7, July 2014, PG-(10807-10867)

[13] Khandker Tawfique Ahmed, Mithun Datta, Nur Mohammad, A Novel Two Switch Non-inverting BuckBoost Converter based Maximum Power Point Tracking System, IJECE, Vol. 3, issue: 4, August 2013, pg-( 467 477)

\section{Author Profile}

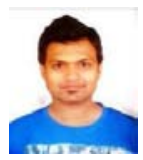

Aamir Khan has Dual Degree (B.Tech + M.Tech) B.Tech in Electrical Engineering and he is pursuing M.Tech in Energy Engineering at Suresh Gyan Vihar University, Jaipur, Rajasthan, India. He has donehis thesis under the guidance of Professor Hari Kumar Singh, Associate Professor at Suresh Gyan Vihar University, Jaipur, Rajasthan, India 